\title{
A Formação do Conceito de Quantidade: concepções de professores dos Anos Iniciais do Ensino Fundamental
}

\section{The Constitution of the Quantity Concept: conceptions of early grade elementary school teachers}

Valdivina Alves Ferreira *

ORCID iD 0000-0002-2306-7465

\begin{abstract}
Resumo
O artigo apresenta resultados da pesquisa que teve por objetivo identificar e analisar as concepções expressas por professores de Anos Iniciais do Ensino Fundamental sobre formação do conceito de quantidade pelos alunos e como atuam no ensino desse conceito. As análises decorrem de uma pesquisa bibliográfica e empírica com fundamentos na abordagem histórico-cultural, principalmente em Vygotsky e em Davydov. Os resultados mostram que o conceito de quantidade, enquanto conceito nuclear da Matemática, é desconhecido e que as concepções que os professores expressaram estão na perspectiva da lógica formal de formação de conceitos, contribuindo para o resultado fragilizado que temos a respeito da aprendizagem dos estudantes.
\end{abstract}

Palavras-chave: Ensino de Matemática. Ensino Desenvolvimental. Pensamento Teórico.

\begin{abstract}
The article presents results of a research aimed to identify and analyze the conceptions expressed by early grade elementary education teachers on the constitution of the quantity concept by students and how they act when being taught this concept. The analysis derive from a bibliographical and empirical research based on the historicalcultural approach, mainly in Vygotsky and in Davydov. The results show that the quantity concept as a nuclear mathematics concept is unknown and that the conceptions that teachers expressed are in the perspective of the formal logic of concept formation, contributing to the fragile result that we have on student learning.
\end{abstract}

Keywords: Mathematics Teaching. Developmental Teaching. Theoretical Thinking.

\section{Introdução}

$\mathrm{Na}$ abordagem histórico-cultural, sobretudo nas teorias de Vygotsky $(2001 ; 1982 ; 2009)$ e de Davydov (1988; 1982), a formação de conceitos pelos alunos, ou seja, o processo de pensar por conceitos os fenômenos da realidade, é um dos meios mais importantes para a promoção de seu desenvolvimento integral. Considerando-se essa premissa, torna-se relevante que, nos Anos

\footnotetext{
* Doutora em Educação pela Pontifícia Universidade Católica (PUC - Goiás). Docente no Programa de PósGraduação em Educação pela Universidade Católica de Brasília (UCB), Brasília, Distrito Federal, Brasil. Endereço para correspondência: Rua 30 Norte, 3, apto. 909, Águas Claras, Brasília, Distrito Federal, Brasil, CEP: 71918180. E-mail: valdivina5784@ hotmail.com.
} 
Iniciais do Ensino Fundamental, seja proporcionada aos alunos a formação de um dos conceitos básicos em Matemática: o conceito de quantidade.

No Brasil, resultados de pesquisas sobre a formação de conceitos, particularmente os relativos ao conceito de quantidade (fundamental para a formação do pensamento matemático dos alunos), têm sido objeto de discussão. Cedro et al. (2010) apontam que o ensino do conceito de quantidade pode ocorrer de forma voltada ao desenvolvimento do pensamento dos estudantes, especificamente pelo método do geral ao particular e do abstrato ao concreto. Para os autores, sendo o número natural uma particularidade do conceito de número real, no ensino escolar da Matemática, em vez de se começar pelos números naturais, deve-se começar pelos números reais.

Rosa et al. (2011) mostram que, de modo geral, o professor tem ensinado o conceito de número nos Anos Iniciais do Ensino Fundamental a partir da contagem de objetos mostrados aos alunos, enquanto que, para impulsionar o desenvolvimento dos alunos, o ensino deveria considerar os números em um sistema conceitual.

[...] É só no campo dos números reais, tomados em sua dinâmica, atividade e movimento, que o conceito de número reflete sua verdadeira natureza. A relação do número real com o objeto pressupõe a existência de relação entre os naturais, racionais, irracionais e inteiros, ou seja, um sistema de conceitos (ROSA et al., 2011, p. 5).

É nos Anos Iniciais do Ensino Fundamental que se concentra a maioria das crianças que, pela primeira vez, têm contato com os conceitos científicos, aqueles que constituem a base para a aprendizagem de conceitos mais complexos. Ainda que não seja o único fator importante, entende-se que a qualidade do ensino e da aprendizagem de conceitos, nessa etapa, dependem fortemente da atuação do professor, de seu modo de organizar o ensino e de promover a atividade dos alunos para que entrem em um trabalho teórico-prático com os conceitos de maneira contextualizada.

Embora a aquisição de conceitos matemáticos pelos alunos dependa significativamente da atividade de ensino do professor, não se pode pressupor que o professor não possua um conceito de quantidade e que, por isso, não o tenha ensinado aos alunos. Para além de atribuir ao professor o baixo desempenho dos alunos, faz-se necessário compreender o que se encontra na base da sua atividade de ensino, em quais concepções esse docente se fundamenta, quais conceitos possui acerca do que ensina e como essas concepções e conceitos fundamentam (ou não) sua atividade docente e a forma de organizá-la.

Diante do exposto, apresentamos neste trabalho os principais resultados de uma pesquisa que teve por objetivo analisar as concepções expressas por professores de Anos 
Iniciais do Ensino Fundamental sobre formação de conceito de quantidade pelos alunos e como atuam no ensino desse conceito.

A seguir, apresenta-se sinteticamente o referencial teórico que fundamentou a pesquisa, a metodologia e os principais achados na análise das categorias e as considerações finais.

\section{O processo de formação de conceitos: contribuições de Vygotsky e Davydov}

Vygotsky foi o primeiro teórico a explicar a formação de conceitos a partir de uma abordagem que leva em conta os aspectos social e cultural, como também o movimento histórico no processo de formação de conceitos. Entre os problemas científicos aos quais se dedicou Vygotsky, está o esclarecimento de como ocorre o processo de formação de conceitos na infância.

Vygotsky (2009) distinguiu dois tipos de conceitos: os conceitos cotidianos e os científicos. Os primeiros abarcam os conhecimentos adquiridos no dia a dia, de forma espontânea; os segundos são os adquiridos na escola, não de forma espontânea, e sim de forma sistematizada, por mediações exercidas de maneira intencional e com objetivos bem definidos. O ensino escolar, portanto, constitui-se como uma ponte para a transição do pensamento da criança dos conceitos cotidianos aos conceitos científicos. Explica o autor:

\footnotetext{
Se nos conceitos espontâneos a criança conhece o objeto representado no conceito, mas não toma consciência do próprio conceito, nos conceitos científicos o início ocorre onde pára o conceito espontâneo, ou seja, na explicitação do seu conteúdo, na definição verbal e mediante operações que pressupõem o emprego não espontâneo dele (VIGOTSKI, 1982, p. 250).
}

Essas ideias de Vygotsky permitem sustentar a defesa de que a formação de conceitos científicos de Matemática nos Anos Iniciais do Ensino Fundamental possibilita ao aluno a formação da capacidade de generalização do pensamento matemático como condição de novas aprendizagens e capacidades de pensar e agir com a Matemática em seus contextos socioculturais. E, por isso, corresponde à etapa inicial do processo de formação dessas capacidades.

Davydov (1988) ampliou as premissas teórico-metodológicas de Vygotsky (2009) para o ensino escolar, formulando a teoria do ensino desenvolvimental. Essa teoria valoriza a formação de conceitos científicos como base para o ensino e aprendizagem escolar, ou seja, como meio primordial de promoção do desenvolvimento do aluno. Nessa teoria, Davydov entrelaça conceitos psicológicos e pedagógicos a fim de explicar a estrutura geral básica da atividade no processo de ensino e de aprendizagem. 
No processo de formação de conceitos, Davydov (1988) considera que é comum a generalização ser compreendida como o processo pelo qual os alunos analisam e comparam os objetos apresentados pelo professor, com semelhanças entre si, devendo distingui-los e identificar suas qualidades comuns. Nesse caso, a definição do conceito corresponde à enumeração das qualidades gerais dos objetos. O aspecto geral torna-se algo que se repete, invariável e, portanto, definidor das propriedades dos objetos. Esse tipo de generalização conceitual permite à pessoa apenas enxergar em cada objeto concreto o que é comum a toda uma classe de objetos.

\subsection{A lógica dialética e a constituição do pensamento teórico}

Davydov, juntamente com os pedagogos e psicólogos russos de sua equipe, colocou como um problema a ser respondido cientificamente, a aplicação dos princípios do pensamento dialético para organização da atividade de ensino com intuito de realizar a formação de conceitos pelas crianças. Ao enfatizar o conceito de atividade introduzido na ciência contemporânea pela lógica dialética, Davydov (1988, p. 12) ressalta seu núcleo:

A razão pensante (a mente) exacerba a diversidade do diverso para o ponto de oposição. Somente as ideias diversas (díspares), elevadas a este nível, se tornam reciprocamente móveis e, dessa forma, podem ser entendidas em seu automovimento e vitalidade internos. Falando do "núcleo da dialética".

É pelo procedimento de ascensão do abstrato ao concreto que é possível realizar a reprodução teórica do concreto real como unidade do diverso (DAVYDOV, 1988). Significa que, no pensamento humano, o objeto ou fenômeno concreto aparece como uma síntese resultante de seu trabalho mental e como ponto de partida que serviu a sua atividade pensante. Inicialmente, o objeto é captado sensorialmente, como uma etapa para ser captado e reproduzido idealmente em suas conexões internas universais, expressando o seu movimento em uma lógica conceitual.

Para realizar esse movimento, são necessárias abstrações do tipo teórico; e a abstração pela qual começa o pensamento teórico tem, como conteúdo, a conexão histórica do objeto, sua integralidade e universalidade. Ademais, as contradições dessa conexão devem refletir também sua essência:

Sendo um aspecto do concreto, isto é, tendo sua forma peculiar, esta conexão aparece, simultaneamente, como fundamento genético do todo (e neste sentido aparece como universal). Aqui se observa a unidade do singular (peculiar) e do universal, objetivamente existente, a conexão que mediatiza o processo de desenvolvimento do todo (DAVYDOV, 1988, p. 82).

Para referir-se a essa abstração inicial, o autor utiliza as denominações "célula" ou 
“abstração substantiva". Ainda, para melhor elucidar, questiona por que denominá-la abstração se ela na verdade é real e observável. Então, explica:

O abstrato e o concreto são momentos do desmembramento do próprio objeto, da realidade mesma, refletida na consciência e por isso são derivados do processo da atividade mental. A confirmação da objetividade de ambos os momentos é a peculiaridade mais importante da dialética como lógica (DAVYDOV, 1988, p. 83).

A abstração substantiva aparece como objeto simples, não desenvolvido, homogêneo, que ainda não atingiu as necessárias diferenciações. Por isso, ela é a abstração geneticamente inicial de um objeto. Externamente ao pensamento humano, os objetos e fenômenos existem como singulares, particulares, concretos, sendo desenvolvidos a partir de uma relação real, que contém um aspecto essencial, uma "célula". Nessa célula está sua natureza universal, base de todas as formas pelas quais o objeto aparece de maneira particular.

Para acessar um objeto por essa forma de pensamento - partir de um fenômeno superficial, em seu imediatismo, chegar a compreendê-lo de forma mediada, em sua essência são necessárias as ações de abstração, de generalização e, por fim, de expressão do objeto na forma de conceito teórico. Por meio do conceito teórico e abstrato alcançado, os fenômenos particulares são analisados, deduzindo-os da base universal (DAVYDOV, 1988).

Para o autor, o pensamento teórico se realiza no plano das ações mentais, isto é, como experimento mental com os objetos de conhecimento. O produto desse procedimento é o conhecimento sobre o objeto, a aprendizagem. O conceito teórico aparece como unidade a partir da redução da diversidade como conceito que "serve de procedimento para deduzir os fenômenos particulares e singulares de sua base universal" (DAVYDOV, 1988, p. 87).

\section{O ensino para a formação de conceitos teóricos e o conceito de quantidade}

Davydov defende que a aprendizagem deve ter como conteúdo o conhecimento teórico (pensamento teórico) como meio de formação de conhecimentos sistematizados e legitimados pela cultura humana. E o professor estrutura para os alunos tarefas que lhes propiciem operar mentalmente com os objetos do conhecimento conforme o "caminho percorrido pelo pensamento científico" (DAVYDOV, 1988, p. 92). A formação do conceito deve dar-se por um processo investigativo realizado por meio de uma tarefa cognitiva que requer do aluno a identificação da relação geral básica do conteúdo aprendido e, depois, a descoberta de que essa relação está presente em muitas relações particulares.

Primeiramente, o professor auxilia os alunos a realizarem a abstração substantiva, que deve ser então registrada como uma relação geral básica. Após, os alunos irão descobrir os 
vínculos regulares dessa relação com outras manifestações particulares para, assim, chegarem a uma generalização substantiva do conteúdo estudado. Esse processo de abstração e generalização, ao ser utilizado pela criança para deduzir e unir as relações gerais às relações particulares, permite a ela compreender o conceito que representa o núcleo do conteúdo.

Para Davydov (1988), a tarefa é a união do objetivo com a ação para que, sob certas condições, o objetivo seja alcançado. Por meio da tarefa, o professor apresenta aos alunos as exigências de procedimentos mentais: 1) generalização e abstração substantivas: análise do conteúdo (objeto) para a descoberta da relação geral, governada por uma lei e vinculada às diversas manifestações ou relações particulares desse conteúdo; 2) construção do "núcleo" do objeto: com base na generalização e abstração substantivas, dedução das relações particulares do objeto em união com sua totalidade; 3) análise e síntese: por meio desse processo o aluno conhece o objeto estudado, dominando o procedimento geral que serviu à sua construção.

Davydov (1988) formulou etapas compondo o caminho a ser percorrido pelo aluno e assegurado na estruturação da sua tarefa pelo professor (FREITAS, 2011). Essas ações, formuladas por Davydov, são uma base geral para o ensino. Cada uma delas e suas correspondentes operações variam conforme o conteúdo em função do conceito a ser formado e das condições concretas em que se resolve uma ou outra tarefa de aprendizagem.

Para o autor, se o professor pretende que o aluno forme o pensamento teórico, deve organizar tarefas adequadas para tal. Nessa organização, o professor pode propor que se parta das teses gerais da área da Matemática, não dos casos particulares, sugerindo tarefas pelas quais a compreensão do conceito de número seja produzida pelo aluno.

$\mathrm{O}$ autor enfatiza a possibilidade de familiarizar o aluno, primeiramente, com esse objeto geral (a quantidade) e, só depois, deduzir os casos mais particulares, especificamente decorrentes de sua manifestação: a Aritmética, a Álgebra e a Geometria. Ele também indica as etapas a serem respeitadas na elaboração da atividade de ensino: na primeira, o aluno opera com objetos e gravuras ao destacar os parâmetros de grandeza; na segunda, usa signos para registrar as relações obtidas por meio de comparações entre as grandezas; na terceira registra literalmente o resultado encontrado a partir das relações de comparação. Nessa atividade, evidenciam-se as condições mediante as quais se compreende a essência do conceito de número, mostrando a sua origem, conceito nuclear da Matemática, o conceito de quantidade.

Daí decorre a importância de que o professor desse nível de ensino, particularmente o docente dos Anos Iniciais do Ensino Fundamental, tenha conhecimento aprofundado sobre o que é um conceito, como é o processo de formação de conceitos pelos alunos, o que é o conceito de quantidade, e como organizar o ensino para que os alunos o compreendam. É a partir do 
conceito de quantidade que o aluno estabelece relações com os demais conceitos da Matemática.

\section{Encaminhamento metodológico}

O percurso metodológico foi guiado pela perspectiva da pesquisa qualitativa que, segundo Bogdan e Biklen (1994), viabiliza a geração de dados para a compreensão da maneira como se expressa o pensamento dos indivíduos participantes do processo de investigação. Os estudos com abordagem qualitativa permitem compreender o dinamismo interno das situações reais observadas e o significado que os sujeitos atribuem às coisas. O movimento de aproximação dos aspectos pertinentes à realidade permite a construção de certa leitura dessa realidade, afirma Pires (2008).

De acordo com Flick (2009, p. 25), "a pesquisa qualitativa não se baseia em um conceito teórico e metodológico unificado". Segundo esse autor, os métodos qualitativos levam em consideração a comunicação do pesquisador em campo e a subjetividade como parte do processo de pesquisa. Destaca, ainda, que a pesquisa qualitativa analisa casos concretos em suas "peculiaridades locais e temporais, partindo das expressões e atividades das pessoas em seus contextos locais" (FLICK, 2009, p. 37).

Assim, o cenário escolhido para a realização da pesquisa foi o Ensino Fundamental Anos Iniciais na rede municipal de Educação de Goiânia - Goiás, no Brasil. O sistema municipal de ensino de Goiânia é constituído por $\operatorname{ciclos}^{1}$. Nesse sistema de ensino organizado em ciclos, o primeiro ciclo atende alunos na faixa etária de 6 a 8 anos, o segundo ciclo atende alunos na faixa etária de 09 a 11 anos, e o terceiro ciclo é responsável pelo atendimento de alunos na faixa etária de 12 a 14 anos. Os três ciclos correspondem aos nove anos do Ensino Fundamental (GOIÂNIA, 2011). Dentro de um contexto de pesquisa qualitativa foram consideradas sete escolas da zona urbana de Goiânia (Goiás).

Definidas as escolas ${ }^{2}$, fez-se o contato com a Secretaria Municipal de Educação de Goiânia (SME), obtendo autorização para a realização da pesquisa. Mediante autorização da SME, partiu-se para a seleção dos sujeitos. A ética na pesquisa qualitativa é "uma questão

\footnotetext{
${ }^{1}$ Proposta Político-Pedagógica para a Educação Fundamental da Infância e da Adolescência, aprovada pelo Conselho Municipal de Educação de Goiânia, por meio da Resolução n. 240, de 17 de dezembro de 2008, prorrogada pela Resolução CME n. 128, de 29 de agosto de 2011. O ensino por meio de ciclos consiste em uma maneira de organização escolar do Ensino Fundamental, contida na Lei de Diretrizes e Bases (LDB) 9394/1996.

${ }^{2}$ Optou-se por definir como cenário do campo de pesquisa as escolas que obtiveram a maior nota e as menores notas do IDEB 2009, na zona urbana de Goiânia.
} 
fundamental no planejamento e na execução da pesquisa" (FLICK, 2009, p. 56). Foi solicitado o consentimento dos participantes em formulário próprio, bem como a confidencialidade na redação da pesquisa.

Na Lei de Diretrizes e Bases da Educação Nacional - LDB 9394/96, os Anos Iniciais do Ensino Fundamental vão do $1^{\circ}$ ao $5^{\circ}$ ano. A realização de ações envolvendo o conceito de quantidade é esperada no final dos Anos Finais do Ensino Fundamental, juntamente com a habilidade do aluno em executar ações com esse conceito na área da Matemática. A definição do $1^{\circ}$ ao $6^{\circ}$ ano, como objeto de investigação, se deu por ser nos Anos Iniciais do Ensino Fundamental que o aluno tem acesso ao ensino do conteúdo quantidade, conforme o Projeto Pedagógico da Secretaria da Educação do município.

Delimitados os ciclos a serem investigados, definiu-se então a amostragem no processo de pesquisa qualitativa, ou seja, os professores sujeitos da pesquisa, aplicando-se critérios de inclusão: fazer parte do corpo docente das sete escolas como professor efetivo, atuando no $1^{\mathrm{o}} \mathrm{e}$ $2^{\circ}$ ciclo; estar efetivamente atuando na docência dos Anos Iniciais do Ensino Fundamental no momento da investigação empírica e, nessa atuação, ensinar conteúdos de Matemática; não estar afastado da atuação na docência por motivo de licença ou por qualquer outro; concordar, voluntariamente e livremente, em participar da pesquisa.

Nas sete escolas autorizadas pela SME para a realização da pesquisa empírica havia quinze professores que correspondiam aos critérios de inclusão nessa investigação, e, ao serem contatados, aceitaram participar da pesquisa, assinando o termo de Consentimento da Participação da Pessoa como Sujeito na pesquisa e a Declaração de Autorização para Gravação em Áudio e Vídeo.

Antes de iniciar a geração de dados in loco, quatro professoras foram excluídas, uma por entrar em licença-maternidade, três por se recusarem no momento da coleta de dados, embora já tivessem aceitado anteriormente. $O$ total de sujeitos foi reduzido a onze docentes.

Para a obtenção de dados foram utilizadas as técnicas de entrevista semiestruturada e a observação das aulas de Matemática dos professores no $1^{\circ}$ e $2^{\circ}$ ciclos. De acordo com Flick (2009, p. 205), "a triangulação de observações com outras fontes de dados, aliada ao emprego de diferentes observadores, intensificam a expressividade dos dados assim reunidos". A técnica de entrevista tangenciou conhecer a experiência do professor, pondo em relevo sua compreensão sobre formação de conceitos e o conceito de quantidade. As entrevistas foram realizadas individualmente com os onze professores, previamente agendadas, em horário de estudo destinado ao professor em sua respectiva escola.

O roteiro da entrevista teve como suporte as categorias teóricas de estudo, delineadas 
previamente e que serviram de norte para a busca de respostas ao questionamento da pesquisa. Flick (2009) compreende que a análise de conteúdo é um dos procedimentos clássicos para se proceder à análise de material textual sendo que "uma de suas características essenciais é a utilização de categorias, as quais são normalmente obtidas a partir de modelos teóricos" (FLICK, 2009, p. 291). Nesse caso, segundo esse autor, é possível levar categorias para o material empírico e não se desenvolver a partir do mesmo (FLICK, 2009). Assim, empregouse as seguintes categorias: a) a formação de conceitos e o conceito de quantidade, b) o ensino para a formação do conceito de quantidade dos professores. Essas duas categorias guiaram as perguntas feitas aos professores, no intuito de aproximar-se das representações desses professores sobre o conceito de quantidade e sua importância para o ensino dos conteúdos da Matemática nos Anos Iniciais da Educação Básica.

Outro instrumento de coleta de dados foi a observação. Esse instrumento permitiu o levantamento de informações a partir do convívio profissional com os sujeitos da pesquisa. Assegura Fernandes (2011) que a observação permite estar e observar onde a ação acontece. Assim, buscou-se, por ela, estar e observar onde a ação de ensino de Matemática acontecia, ou seja, a sala de aula. Para realizar a observação construiu-se um roteiro para direcionar a geração de dados, atentando-se às ações de ensino do professor, bem como o comportamento dos alunos durante as atividades. As observações ocorreram nas salas de aula das turmas do $1^{\circ}$ e $2^{\circ}$ ciclo $\left(1^{\mathrm{o}}\right.$ ao $6^{\mathrm{o}}$ ano $)$ do Ensino Fundamental das sete escolas municipais selecionadas em Goiânia.

Durante as observações, o foco foi a ação do professor e seus alunos. A pesquisadora observou 16 aulas. O critério usado na definição do número de aulas foi o princípio de saturação, defendido por Pires (2008). Esse princípio ocorre quando a informação obtida se torna claramente repetitiva durante as seções de observação. Nesse artigo apresentamos cinco episódios observados, uma vez que os demais mostraram os mesmos resultados aqui analisados.

Antes de iniciar as seções de observação em sala de aula, os sujeitos da pesquisa foram informados sobre os objetivos da observação e a forma como isso ocorreria. Tinha-se como objetivo buscar evidências que mostrassem como o professor organiza o ensino dos conceitos matemáticos e como o conceito de quantidade, enquanto conceito nuclear da Matemática, é tratado por esse professor ao ministrar a sua aula. Foram informados também que a pesquisadora faria apenas a observação e não participaria de nenhuma atividade durante a realização da aula. Esse procedimento é intitulado por Flick (2009, p. 204) de "observação não participante". O registro dos dados então coletados ocorreu por meio de anotações sobre a ação do professor e dos alunos (discursos, interações), complementadas com gravação em áudio e vídeo. O material obtido durante as observações foi organizado em categorias de estudo 
possibilitando, assim, a sistematização.

A organização dos dados obtidos por meio das observações correspondeu às categorias de análise de estudo, citadas anteriormente: a formação de conceitos e o conceito de quantidade, o ensino para a formação do conceito de quantidade dos professores no ensino e aprendizagem da Matemática.

Para a análise dos dados, após o processo de produção e organização sistemática das transcrições das entrevistas e das observações, como orientam Bogdan e Biklen (1994), recorreu-se à leitura em profundidade do conjunto do material buscando explicar o que pensam e como agem esses professores em sua dinâmica de trabalho ao ensinarem os conceitos nas aulas de Matemática.

Antes de apresentar os dados constitutivos dessas categorias, considera-se importante conhecer a formação e a atuação desses sujeitos. Dos onze professores, dois eram licenciados em Matemática e possuíam especialização na área. Nove eram pedagogos e apenas cinco deles possuíam especialização na área de sua formação. Entre eles, nove professores atuavam também em outras escolas como docentes e dois ministravam aulas somente nas escolas pesquisadas.

\section{A concepção dos professores dos Anos Iniciais do Ensino Fundamental sobre a formação do conceito matemático quantidade}

Nesta seção, são apresentados os principais resultados da pesquisa relatada neste artigo, sobre as concepções expressas pelos professores sobre conceito matemático de quantidade. Nessa descrição, os professores são referidos por números que correspondem à sequência de sua inclusão na pesquisa. Na busca do entendimento acerca do processo de formação de conceito e, especificamente, do conceito de quantidade, foi-lhes pedido, durante a entrevista, que descrevessem como compreendiam este conceito e que referências tinham para essa compreensão.

Foi interessante observar que, por mais que se insistisse e reformulasse de diferentes modos a pergunta, os professores entrevistados não chegavam a tratar exatamente do que se perguntava. Dos professores participantes, a maior parte deles (dez) relatou que conceito é definição de algo. A exceção foi a Professora 05 que mencionou que um conceito corresponde ao significado de algo, é saber sobre algo expresso em uma palavra. Eis um trecho da resposta dada pela Professora 5:

Na minha visão [conceito] é trabalhar o significado de algo. Saber sobre algo, o que significa. [...] O que seria a palavra adição? Nessa palavra [...] seria perceber quando a criança 
desenvolveu a capacidade de adicionar e ela consegue distinguir isso no dia a dia. Na hora que ela tem um probleminha, ela vai contar os lápis e ver se está tudo certo. É quando eu vejo no fazer da criança que ela realmente aprendeu.

(Entrevista com a Professora 05, licenciada em Pedagogia, 2013).

A forma pela qual a professora conclui que o aluno formou o conceito passa pela dimensão empírica e não teórica: “quando ele conta os lápis”. Verifica-se aí a presença da lógica formal como descrita por Davydov (1988), fundamentando a compreensão da professora: conceito é o significado de algo expresso na palavra, no caso a palavra "adição", de acordo com a Professora 05. Assim, o fato de a criança ser capaz de adicionar no dia a dia não é sinônimo de formação do conceito de adição. A criança já faz esse tipo de operação antes mesmo de ir à escola pela primeira vez.

Ao perguntar aos professores sobre como compreendem o conceito de quantidade enquanto conceito nuclear da Matemática, e a partir de quais referências têm essa compreensão, as respostas obtidas foram variadas.

[...] Sobre a quantidade eu sempre trabalhei com meus alunos - os números, a sequência [...] (Entrevista com a Professora 02, Licenciatura em Pedagogia, 2013).

A primeira vez que ouvi sobre isso [conceito nuclear] foi quando você veio falar com a gente a primeira vez e explicou sobre o seu projeto.

(Entrevista com a Professora 04, licenciada em Pedagogia, 2013).

Eu nunca ouvi falar sobre isso. Só você.

(Entrevista com a Professora 05, licenciada em Pedagogia, 2013).

Eu não sei [...] nunca ouvi falar [...]

(Entrevista com a Professora 07, licenciada em Matemática e Especialista em Estatística, 2013).

Os professores 1, 3, 8, e 11 também relataram desconhecer o conceito de quantidade, enquanto conceito nuclear da Matemática e disseram que foi a primeira vez que ouviram essa expressão. Ao ouvirem que grandeza e quantidade têm o mesmo significado, duas professoras, a Professora 10 e a Professora 11, relacionaram esse conceito ao bloco de Grandezas e Medidas que faz parte dos Parâmetros Curriculares Nacionais (BRASIL, 1988).

A questão da grandeza no Ensino Fundamental é como você vai ensinar o maior, o menor, tamanho dos objetos, o tamanho das medidas - medidas de comprimento, a quantidade, o material de contagem que temos na sala de aula.

(Entrevista com a Professora 11, licenciada em Pedagogia, 2013).

A questão das grandezas é importante, pois a criança vive esse conteúdo no seu dia a dia, ele sempre está perto do que é grande, pequeno e também do valor das coisas, só que esse conteúdo fica prejudicado, pois é sempre dado no final do ano.

(Entrevista com a Professora 10, licenciada em Matemática, 2013).

O entendimento expresso pelas Professoras 11 e 10 sobre o conceito, ou seja, o procedimento mental, de grandeza relaciona-se não ao conceito de quantidade como um 
conceito nuclear, mas como um conceito específico, particular. Para Davydov (1982), grandeza é uma relação elementar entre as qualidades que atribuímos aos objetivos do ponto de vista da quantificação. Compreender esse conceito como o fundamento geral dos tipos de número natural, é essencial na organização do ensino, já que, conforme afirmação de Davidov (1988, p. 113-114), “as propriedades das quantidades são descobertas quando uma pessoa está operando com reais extensões, volumes, pesos, períodos de tempo e assim por diante (mesmo antes de terem sido expressos em números)".

Durante a entrevista e na observação das aulas, a forma predominante por todos os onze professores para o ensino do conceito de quantidade foi a de mostrar a sequência dos números, relacionando-os com figuras contendo a quantidade correspondente ao número. Essa sequência é obedecida sempre iniciando pelo numeral 1, na sequência o 2 e assim sucessivamente. A preocupação dos professores, então, parece ter sido a de apresentar aos alunos a ideia de uma relação direta do número/símbolo com a quantidade de objetos em referência. Ou seja, a figura de dois patinhos representa o número 2, os quatro pés de uma mesa correspondem ao número 4 etc.

Para os professores, o fato de mostrarem as figuras ou qualquer outro objeto manipulável ou visível, estabelecendo sua correspondência com o número, possibilita ao aluno compreender a relação entre número e o numeral, ou seja, entre a ideia e a sua representação literal. Veja o que expressa o Professor 11:

A gente já trabalha esse conceito há muitos anos e não sabia [que era isso]. Até mesmo a ordem dos números né, você coloca o número 5, coloca cinco tampinhas no cinco; quatro no quatro [...] O número não é só escrito, ele representa uma quantidade [...], qual o número é maior.

Entrevista com o Professor 11, licenciado em Pedagogia, 2013).

Outra forma referida pela maior parte dos professores para ensinar o conceito de quantidade foi a decomposição dos números. Ao propor a decomposição, as Professoras 5, 7 e 10 relataram que aproveitam para mostrar ao aluno a relação existente entre o maior e o menor número, fazendo comparações entre os diferentes números apresentados.

A Professora 11 mostrou preocupação de que em seu planejamento fossem priorizadas ações que envolvessem o aluno para que conseguisse ver a relação do conceito ensinado com os outros conceitos da Matemática, o que indica que, em sua concepção, o conceito de quantidade abrange um universo maior na Matemática. Talvez ela não tenha podido expressar em uma linguagem matemática o que é esse conceito: “a questão da quantidade na sala de aula é como você vai ensinar o maior, o menor, tamanho dos objetos, o tamanho das medidas, medidas de comprimento, a quantidade, o material de contagem que temos na sala de aula" (Entrevista com a Professora 11, licenciada em Pedagogia, 2013). Os dados indicam que, 
possivelmente, essa professora não se apropriou da forma lógico formal do conceito de quantidade, mas consegue compreender o conceito de quantidade dentro de um universo maior na Matemática.

Ao responderem sobre como identificam se o aluno aprendeu o conceito, todos os professores responderam que sabem que o aluno aprendeu quando ele realiza sozinho a tarefa e acerta a resposta; ele faz as contas mentalmente sem precisar escrever no caderno; ele é capaz de mostrar como conseguiu chegar ao resultado da tarefa.

A solução independente de uma tarefa é considerada por Vygotsky (2009) como resultado de uma aprendizagem que, consequentemente, alterou a capacidade psíquica do aluno e ampliou seu desenvolvimento. Também Davydov $(1982 ; 1988)$ descreve a solução de tarefas de modo autônomo e monitorado pelos próprios alunos como indício de aprendizagem do material ensinado. Nesse caso, pode-se inferir que os professores entrevistados expressaram uma concepção que se aproxima das ideias desses autores. No entanto, se considerarmos que as concepções expressas pelos professores sobre formação de conceitos evidenciam como base as abstrações e generalizações de caráter empírico, não podemos concluir que, por valorizar a efetivação da tarefa como evidência de aprendizagem, os professores sujeitos do estudo possuem uma concepção próxima à de Vygotsky e de Davydov.

Dando sequência, serão descritos alguns episódios observados durante as aulas de Matemática e que subsidiaram o entendimento sobre como esses professores atuam em sua prática pedagógica a partir da concepção que demonstram ter sobre o processo de formação de conceitos matemáticos. Vejamos o episódio a seguir:

A professora inicia a aula falando aos alunos qual seria o conteúdo: formas geométricas triângulo, quadrado e círculo. Começa mostrando a figura do quadrado recortado em cartolina. Pergunta: quem sabe que forma geométrica é essa? Alguns alunos disseram que era quadrado e outros ficaram em silêncio. Ela diz aos alunos:

Olha só, o quadrado é uma das formas geométricas [...] essa figura aqui representa o quadrado. Observe como é feito o quadrado: o quadrado tem quatro lados iguais. Olha só cada parte dessas representa um lado [aponta para os lados do quadrado, um a um]. Agora, olha aqui essas pontinhas do quadrado: são os seus vértices. Veja: essa pontinha aqui é um vértice, essa outra é o segundo vértice, essa o terceiro vértice e essa o último vértice. O quadrado tem quatro vértices e quatro lados iguais.

(Gravação em áudio e visual da aula da Professora 08, licenciada em Pedagogia, 2013).

No meio da explicação, um aluno pergunta: “o que é um retângulo? ”. A professora responde mostrando o quadro-negro e a janela como exemplos de retângulo. Na sequência fala sobre o triângulo, caracterizando-o de acordo com três lados, três vértices, comparando-o com as dimensões do quadrado. Usa o mesmo procedimento ao falar sobre o quadrado para 
introduzir o conceito de triângulo: expõe verbal e visualmente cada uma das figuras geométricas. Na sequência, conta uma história cujo personagem principal era o Geométrico [o Geométrico era feito de um triângulo, um quadrado e um círculo], e finaliza com a entrega de uma tarefa xerocopiada, onde cada aluno teria que construir uma casinha usando duas das formas geométricas: o quadrado e o triângulo.

A curiosidade da criança com relação ao conceito de retângulo foi dirimida com a explicação verbal da professora sobre os atributos que caracterizam essa forma geométrica e a comparação com as dimensões de outra figura: o triângulo. Estabelecer as relações existentes entre os atributos que constituem cada figura é importante para que a criança perceba as diferenças existentes entre ambos e saiba identificar cada um deles, diferenciando-os das demais figuras. Em todo o percurso da aula a interação da criança com o objeto da aprendizagem só ocorreu no final, sendo a exposição oral realizada apenas pelo professor. Aqui se observa a característica de uma aula padrão: a exposição verbal pelo professor mostra-se como recurso didático inicial e finaliza com a tarefa de verificação da aprendizagem, ou melhor, repetição do exposto pelo professor.

Depreende-se que nesse episódio não apareceram as etapas que compõem o caminho para a apropriação do conceito, defendidas por Davydov (1988): a identificação da relação universal do objeto estudado, a representação da relação universal do objeto, a extração do núcleo do objeto de suas manifestações particulares, a aplicação desses procedimentos a outros casos particulares e a avaliação do resultado do procedimento com vistas ao resultado alcançado na resolução da tarefa ali proposta.

Um outro episódio envolvendo uma aula sobre operações com frações de denominadores diferentes mostra que, enquanto a professora fazia a correção da tarefa no quadro-negro, uma aluna levanta a mão e pergunta à professora como ela fez para chegar àquele resultado. A professora chama a aluna até o quadro-negro e começa a detalhar como deve ser pensada a transformação de uma fração com denominadores diferentes em frações com denominadores iguais. Ao efetuar a adição de $1 / 6$ mais $3 / 4$, foi resolvida primeiramente a questão dos denominadores, tornando-os iguais por meio da descoberta do mínimo múltiplo comum e, depois, realizada a soma dos numeradores conservando-se os denominadores. Nessa ação a aluna realiza os procedimentos para encontrar a resposta à sua própria pergunta. Houve um envolvimento mental da aluna com o conteúdo objeto de estudo.

Davydov (1999) afirma que o desejo é a base da necessidade e não pode ser entendido separadamente. Ambos surgem a partir de manifestações emocionais. A aluna compreendeu o procedimento a ser efetuado na resolução de operações de adição de frações com 
denominadores diferentes, mas será que teve a oportunidade de compreender o porquê da necessidade de se chegar ao denominador comum para só em seguida realizar a operação? O processo de formação de conceitos exige, na lógica dialética, que se forme nas crianças o conceito de frações a partir das "manifestações da relação múltipla geral de quantidades sob determinadas condições concretas", sendo preciso compreender a "interconexão dos elementos nas ações aritméticas básicas”, afirma Davydov (1988, p. 114).

Um terceiro episódio a ser detalhado foi o uma aula sobre simplificação de frações. $O$ professor colocou várias frações no quadro e demonstrou o que fazer, explicando que para simplificar uma fração é necessário dividir o seu numerador e o seu denominador pelo mesmo número. $\mathrm{O}$ professor insiste para que os alunos verbalizem todas as etapas percorridas para realização da atividade para, só então, chegar ao resultado. A verbalização, por parte do aluno, dos procedimentos a serem adotados na resolução de uma tarefa é considerado importante pela teoria histórico-cultural, porém, não é suficiente para que esse aluno compreenda o conceito de determinado objeto.

Há outras ações que o aluno deve realizar para garantir a aprendizagem: operar físico e mentalmente com objetos e figuras quando vai identificar os parâmetros de quantidade; o uso de signos (escrita) para registrar as relações que encontrou por meio de situações que permitiram comparações entre as quantidades e ainda ser capaz de registrar, de forma exata, o resultado que obteve a partir das relações de comparações, defende Davydov (1982). A qualidade dos vínculos do pensamento do aluno com as coisas do mundo fica restrita aos nexos empíricos se o grau de organização da atividade de ensino não privilegiar a formação do conceito de quantidade como forma basilar dos conceitos tratados na Matemática.

O episódio a seguir ilustra uma atividade na qual foi mostrado ao aluno um conjunto de objetos a serem observados e comparados. Ao aluno é solicitado apenas que realize a localização das características numéricas correspondentes a cada elemento, em uma relação biunívoca para, em seguida, distribuir esses elementos em partes iguais, nomeando, assim, os signos numéricos daquela coleção. Prevalecem, como característica, o caráter lúdico e o entendimento de que é apenas necessário à criança associar os números às figuras e aos animais e fazer a correspondência biunívoca. Após distribuir uma tarefa em folha A4, a Professora 02 indaga aos alunos: “O que vamos fazer agora?" (Professora 2, 2013). A aula continua com a indagação da professora sobre como fariam para distribuir doze peixes em quatro aquários. Ela desenha os aquários no quadro negro e faz a distribuição dos peixes um a um em cada aquário, acompanhada pelos alunos, que iam falando o que devia ser feito. A docente finaliza a atividade e passa para a tarefa seguinte usando o mesmo procedimento realizado com a distribuição dos 
peixes em seus respectivos aquários.

Mais uma vez, a organização do ensino planejado pela professora privilegia apenas ações centradas em sua pessoa. A relação entre quantidades foi explorada, mas de forma empírica. Desconhecer o conceito de quantidade por parte do professor é um fator que dificulta o ensino e, consequentemente, a aprendizagem do aluno. A tarefa apresentada poderia ser explorada levando em conta todas as ações (DAVYDOV, 1982) a serem observadas na formação do conceito de quantidade pelo aluno.

Libâneo e Freitas (2013, p. 343), em interlocução com Davydov, mostram que o professor, ao organizar uma tarefa de aprendizagem, deve considerar certas ações de estudo, sendo uma delas a modelagem. Nela os alunos são orientados a criarem um "modelo representativo da relação universal de suas conexões internas. Este modelo, que já é um produto de análise mental e pode ser criado em forma gráfica, literal ou objetivada”. Assim, observa-se outro episódio que, ao ensinar operações de adição e subtração com denominadores diferentes, a professora iniciou pedindo aos alunos para trabalharem em grupos. Entregou uma folha A4 a cada um do grupo e pediu-lhes para dobrá-la em dezesseis partes iguais, recortar cada parte a ser dividida. Os alunos fizeram a divisão de cada tira até completar dezesseis partes iguais. As tiras divididas foram usadas para mostrar aos alunos a ideia de fração. A Professora explica:

[...] fração é a denominação usada para representar a parte de um todo, consiste na representação de uma quantidade; no caso de um meio (1/2) significa que foi considerada apenas a metade de um inteiro, ou seja, a fração é uma forma de representação de quantidades menores que um inteiro.

(Gravação em áudio e visual da aula da Professora 3, licenciatura em Pedagogia, 2013).

$\mathrm{Na}$ sequência, a professora demonstrou, no quadro, as operações com frações com denominadores diferentes, apresentando uma situação-problema a ser resolvida: "Gabriel tomou um quarto de litro de leite pela manhã. À tarde tomou um terço de litro de leite e a noite um sexto. Que fração de litro de leite ele tomou o dia todo? Quanto ainda sobrou de um litro?" (Professora 3, licenciada em Pedagogia, 2013).

$\mathrm{Na}$ resolução do problema foi elencado o conjunto de informações que compõem seu enunciado: a quantidade de leite que Gabriel tomou que equivale às frações; as frações ainda desconhecidas que são a quantidade total de leite que ele tomou; a quantidade de leite que restou no litro. A seguir, os alunos encontram a fração com denominador comum multiplicando a primeira fração por 2, depois por 3, e assim por diante. O mesmo procedimento foi realizado com as demais frações. Realizam a operação de adição para saber o total de leite tomado e diminuíram de um litro esse total para saber quanto ainda resta de leite no litro. No caso dessa aula observa-se que a professora organiza o ensino considerando o conteúdo a ser ensinado, o 
material manipulado pelo aluno na condução da sua aprendizagem e a preocupação com que o aluno soubesse exatamente o que se espera dele na realização da tarefa.

Mesmo em uma tarefa apresentando as condições necessárias para que o aluno forme o pensamento teórico, a professora utiliza ações nas quais seria possível a modelagem, mas se presencia a inexistência da análise das relações entre as coisas no interior do objeto de estudo e a existência de uma generalização formal das propriedades do objeto, não considerando os laços entre esses objetos. Apesar de manusear as frações representadas pelas fichas de papel A4, os alunos realizam apenas tarefas que priorizam a observação, refletindo sobre as propriedades exteriores dos objetos. Não se identifica, aqui, um esforço na avaliação da qualidade que o conteúdo pode ter para a formação do pensamento lógico-matemático.

Os dados gerados pelas observações permitem afirmar que os professores apresentavam aos alunos tarefas cujas exigências eram para operar com traços sensoriais diretos dos objetos para associarem a eles uma representação de quantidade. Em nenhuma das aulas observadas verificou-se alguma atuação dos professores que buscasse levar os alunos a ultrapassarem a simples descrição dos objetos correspondentes à sua representação numérica para atingirem a descoberta da essência do conceito de quantidade; ou seja, mostrar que o número é o produto de uma relação estabelecida pela ideia de quantidade, formado por uma base, um núcleo: o conceito de quantidade, que só pode ser entendido a partir das inter-relações existentes entre os diferentes tipos de números (DAVYDOV, 1982), por meio do pensamento teórico.

Davydov (1982, p. 303) ilustra a tese do pensamento teórico recorrendo ao exemplo de Spinoza para demonstrar o conceito de círculo:

Spinoza via a essência do círculo no ato de sua origem, de sua construção ("criação"). A definição do círculo deve expressar a causa da origem da coisa dada, o método de sua construção. O círculo segundo esta regra, [...] deve definir-se assim: é a figura escrita por qualquer linha, um de cujos extremos é fixo e o outro móvel. Aqui se indica o método para se obter quaisquer círculos infinitamente diversos.

Observa-se que Spinoza mencionou verbalmente a "idealização de um esquema de atividade que permite o detalhamento da construção e do procedimento de uma ação, utilizando nesse processo de formação o conceito de círculo", usando o compasso, afirma Ferreira (2013, p. 73). A essência do pensamento teórico consiste na compreensão das coisas por meio da análise das condições de sua origem e de seu desenvolvimento histórico.

As práticas desses professores mostraram que suas aulas obedecem a uma sequência que caracteriza a aula padrão dentro da ótica da formação de conceitos de quantidade. Essa aula apresenta indícios que reafirmam o que mostra Davydov (1988) sobre a prática pedagógica pautada no ensino tradicional: se o professor chega a um nível de ensino satisfatório é devido a 
um conhecimento empírico. A formação de conceitos depende essencialmente dos conteúdos e dos processos investigativos conexos a esses conteúdos ao considerar a formação do pensamento na lógica dialética.

Chamou a atenção, nos dados obtidos por meio das observações, que os professores adotam procedimentos de ensino que privilegiam à exposição do conteúdo ou meramente à repetição do que está contido no livro didático. Outro elemento que se destacou na prática do professor foi a presença de uma forma de organizar o ensino que corresponde a uma "aula padrão", geralmente iniciada com uma história, seguida da explicação do conteúdo no quadronegro, com a expectativa de que o aluno compreenda a exposição verbal proferida pelo professor. Depois, supondo que o aluno aprendeu o que foi "explicado", o professor aplica uma tarefa de verificação da aprendizagem.

Nesses episódios constatou-se a predominância de três formas de ensinar: a) mostrar a sequência dos números, relacionando-os com figuras contendo a quantidade correspondente ao número, b) decompor os números e c) mostrar a relação do conceito ensinado com os outros conceitos da Matemática. Em todas as formas de ensinar observadas, ressalta-se o empenho dos professores em procurar criar condições para propiciar aos alunos a apresentação dos conteúdos da Matemática. Cada professor utilizava uma situação diferente na abordagem dos conteúdos no intuito de ensinar os conceitos mesmo sem privilegiar as etapas de organização do ensino defendidas por Davydov (1988).

Nas duas primeiras formas mencionadas, observa-se a dificuldade dos professores no que tange ao processo de formação de conceitos, bem como do domínio do conhecimento didático desse conteúdo. Já na última forma, a professora demonstra preocupação em relacionar o conceito de quantidade com outros conceitos da Matemática. Percebe-se, desse fato, haver uma concepção de conceito próxima àquela defendida por Davydov (1988), distanciada de um pensamento menos descritivo a respeito desse conceito.

Os estudos de Davydov $(1988,1999,1982)$ a respeito da formação do pensamento teórico em Matemática e de conceitos pelos estudantes têm muito a contribuir para o desenvolvimento de um pensamento menos descritivo ou apenas de memorização pelos estudantes. É uma teoria que valoriza os conteúdos científicos escolares e não apenas o caráter memorístico a respeito dos conhecimentos sistematizados pela ciência. A contribuição da pesquisa à prática dos professores pauta-se na possibilidade de reflexão a respeito da formação inicial e continuada dos mestres para ensinarem conceitos de Matemática, as formas de organização dos conteúdos e a busca por uma metodologia que promova o aprendizado do aluno. 
Outra contribuição é a possibilidade de o professor conhecer e apropriar-se da proposta de Davydov visando à atividade de ensino conectada à atividade de aprendizagem do aluno, propiciando a aquisição do pensamento teórico-científico e, consequentemente, a ampliação do desenvolvimento mental dos alunos no processo de formação de conceitos matemáticos.

\section{Considerações finais}

Com base nas premissas teóricas davydovianas, pode-se defender a ideia de que conhecer o processo da formação de conceitos pelos estudantes deve, ou deveria, ser um dos requisitos básicos à atuação profissional do professor no sistema de ensino, particularmente nos Anos Iniciais do Ensino Fundamental, nos quais deveriam ser formados os conceitos básicos da Matemática, imprescindíveis para o desenvolvimento das capacidades intelectuais do aluno para se relacionar com a realidade, agir tendo os conceitos matemáticos como instrumentos. Essa é uma questão de interesse das políticas educacionais e das políticas de formação de professores para a Educação Básica, mas também é uma questão relevante a ser investigada em estudos e pesquisas.

A forma como o professor atua pode ser considerada um indício revelador de sua concepção sobre o processo de formação de conceitos e de como lida com o conceito de quantidade no processo ensino e aprendizagem. A presente pesquisa mostrou que os professores participantes, ensinando Matemática, em suas classes de Anos Iniciais do Ensino Fundamental expressaram, acerca do processo de formação de conceitos pelos alunos, uma compreensão, ainda em construção, para a promoção do desenvolvimento do pensamento matemático dos alunos.

Não é totalmente surpreendente a presença da lógica formal na concepção e na prática dos professores ao ensinarem o conceito de quantidade, uma vez que historicamente esse é o tipo de pensamento predominante na escola de forma geral. Todavia, surpreende o fato de alguns não demonstrarem sequer essa lógica ao falarem sobre o conceito de quantidade. Tal situação pode estar contribuindo para a permanência dos recorrentes problemas no ensino escolar da Matemática enfaticamente descritos na literatura científica sobre o assunto e indicado pelo baixo desempenho dos alunos em avaliações, como o Programa Internacional de Avaliação de Estudantes (PISA), afirma Waiselfisz (2009).

Conclui-se que o desempenho escolar de alunos dos anos iniciais do ensino fundamental em Matemática, provavelmente marcado por diversos fatores do contexto institucional do sistema de ensino e da escola e do contexto sociocultural, pode estar sendo influenciado pela 
compreensão do professor a respeito do processo de formação de conceitos pelo estudante.

Espera-se que os resultados aqui reportados possam ser úteis aos estudiosos e pesquisadores dedicados a Educação Matemática, que sirvam para repensar criticamente a formação e a prática dos professores que ensinam Matemática no Ensino Fundamental. Assim, que contribuam para uma revisão crítica dos princípios teóricos e das práticas nesse nível de ensino, uma vez que as crianças e jovens têm seus direitos, direito a uma educação que promova seu desenvolvimento.

\section{Referências}

BRASIL. Ministério da Educação. Parâmetros Curriculares Nacionais. Introdução: Ensino fundamental. Brasília: MEC/SEF, 1998.

BOGDAN, R.; BIKLEN, S. Nove questões frequentes sobre a investigação qualitativa. Investigação qualitativa em educação: uma introdução à introdução à teoria e aos métodos. Portugal: Porto, 1994, p. 63-71.

CEDRO, W. L. et al. A atividade de ensino e o desenvolvimento do pensamento teórico em matemática. Ciência \& Educação, Bauru, v. 16, n. 2, p. 427-445, 2010.

DAVYDOV, V. V. Problems of developmental teaching - The experience of theoretical and experimental psychological research. Soviet Education, Moscou, v. 10, n. 8, ago. 1988.

DAVYDOV, V. V. Uma nova abordagem para a investigação da estrutura e do conteúdo da atividade. In: HEDEGARD, M.; JENSEN, U. (org.). Activity theory and social practice: culturalhistorical approaches. Aarhus: Aarthus University Press, 1999.

DAVYDOV, V. V. Tipos de generalización en la enseñanza. Habana: Editorial Pueblo y Educación, 1982.

FERREIRA, V. A. A formação de conceitos matemáticos nos anos iniciais: como professores pensam e atuam com conceitos. 2013. 156 f. Tese (Doutorado em Ciências Humanas) - Pontifícia Universidade Católica de Goiás, Goiânia, 2013.

FERNANDES, F. M. B. Considerações metodológicas sobre a técnica da observação participante. In: MATTOS, R. A.; BAPTISTA, T. W. F. (org.). Caminhos para análise das políticas de saúde. Rio de Janeiro: EDUERJ, 2011. p. 262-274.

FLICK, U. Introdução à Pesquisa Qualitativa. 3. ed. Porto Alegre: Artmed, 2009.

FREITAS, R. A. M. M. Aprendizagem e formação de conceitos na teoria de Vasili Davydov. In: LIBÂNEO, J. C.; SUANNO, M. V. R.; LIMONTA, S. V. (org.). Concepções e práticas de ensino num mundo em mudança: diferentes olhares para a Didática. Goiânia: CEPED/Editora PUC Goiás, 2011. p. 71-84.

GOIÂNIA, Secretaria Municipal de Educação. Proposta Político-Pedagógica para a Educação Fundamental da Infância e da Adolescência. Goiânia: SME, 2011.

LIBANEO, J. C.; FREITAS, R. A. M. M. Vasily Vasilyevich Davydov: a escola e a formação do pensamento teórico-científico. In: LONGAREZI, A. M.; PUENTES, R. V. (org.). Ensino 
Desenvolvimental: vida, pensamento e obra dos principais representantes russos. Uberlândia: Editora da Universidade Federal de Uberlândia, 2013. p. 275-305.

PIRES, A. Sobre algumas questões epistemológicas de uma metodologia geral para as ciências sociais. In: POUPART, J. et al. (ed.). A pesquisa qualitativa: enfoques epistemológicos e metodológicos.

Petrópolis: Vozes, 2008. p. 43-94.

ROSA, J. E. et al. Conceito de número no sistema de ensino de Davydov. In: CONFERÊNCIA INTERAMERICANA DE EDUCAÇÃO MATEMÁTICA (CIAEM-IACME), 13., 2011, Recife. Anais... Recife: 2011.

VIGOTSKI, L. S. Manuscrito de 1929. Educação e Sociedade, Campinas, v. 21, n. 71, p. 21-44, 2001.

VIGOTSKY, L. S. Obras escogidas II. Madrid: Visor, 1982.

VYGOTSKY, L. S. A construção do pensamento e da linguagem. 2. ed. Tradução de Paulo Bezerra. São Paulo: Martins Fontes, 2009.

WAISELFISZ, J. J. O ensino das Ciências no Brasil e o PISA. Sangari do Brasil, 2009. Disponível em: http://cms.sangari.com/midias/2/36.pdf. Acesso em: 18 jan. 2011. 